\title{
Lead-Discovery of bis-Aromatic Alkynes: A Novel Class of Herbicides
}

\begin{abstract}
Jutta Glock ${ }^{\mathrm{a}}$, James Allen ${ }^{\mathrm{a}}$, Thierry Niderman ${ }^{\mathrm{a}}$, Hans Ulrich Haas ${ }^{\mathrm{a}}$, Renold Chollet ${ }^{\mathrm{a}}$, Martin Eberle ${ }^{\mathrm{b}}$, Peter Renold ${ }^{a}$, William Lutz ${ }^{\mathrm{a}}$, Jürg Ehrler ${ }^{\mathrm{c}}$, Marian Valentinid, Markus Waltia ${ }^{\mathrm{a}}$, Evelyne Sieger ${ }^{\mathrm{a}}$, Thomas Vettiger ${ }^{\mathrm{a}}$, Hans Brunnera ${ }^{\mathrm{a}}$, Julie E. Penzottie, Peter D. J. Grootenhuis ${ }^{\dagger}$, Steven Bondyg, Daniel D. Comer ${ }^{h}$, Soan Cheng ${ }^{\mathrm{h}}$, Arthur Steiger ${ }^{\mathrm{a}}$, Martin Zeller ${ }^{\mathrm{a}}$, Grit Laue ${ }^{\mathrm{b}}$, Adrian Friedmann ${ }^{\mathrm{a}}$, Olivier Jacoba , Mafalda Nina ${ }^{a}$, Hans-Jürg Widmera ${ }^{a}$, Klaus Kreuzi, and G. Wayne Craig*a
\end{abstract}

Recipients of the Sandmeyer Prize 2007 of the Swiss Chemical Society

\begin{abstract}
The search for new active molecules with novel modes of action and desirable physical properties is an ongoing endeavour. ${ }^{[1,2]}$ This publication describes the follow-up chemistry of a biological hit discovered in the screening system of Novartis Crop Protection, the legacy agrochemical parent of Syngenta Crop Protection. This chemistry was optimized through classical synthetic methods and automated parallel synthesis with coverage of important physical properties such as lipophilicity or Clog $\mathrm{P}$ and solubility. Preliminary biological activity from the greenhouse and field data with symptomology is presented.
\end{abstract}

Keywords: Agrochemicals · Alkyne template $\cdot$ Combinatorial chemistry $\cdot$ Discovery $\cdot$ Sonogashira coupling

\section{Introduction}

There is an abundance of alkyne-containing natural products which exhibit diverse forms of biological activity (Fig. 1). ${ }^{[3]}$ Their structural elements can be found in the spiroketals $\mathbf{1}$ and $\mathbf{2}$, salicylate $\mathbf{3}$, and aromatic alkynes $\mathbf{4 a}, \mathbf{b}$. Many such compounds derive from fatty acid biosynthesis and are reported to show fungicidal,[4a] insecticidal, ${ }^{[4 \mathrm{~b}]}$ and algicidal activity. ${ }^{[4 \mathrm{c}]}$

${ }^{*}$ Correspondence: Dr. G. W. Craig ${ }^{a}$

Tel.: + 41613232708

Fax: + 41613238726

E-mail: cralion@freesurf.ch

asyngenta Crop Protection Münchwilen A.G.

Schaffhauserstr., $\mathrm{CH}-4332$ Stein

bNovartis Pharma A.G., CH-4002 Basel

'Bachem A.G., CH-4416 Bubendorf

dSynkola A.G., SK-842 15 Bratislava, Slovak Republic

e5731 16th Ave NE, Seattle, WA 98105, USA

fVertex Pharmaceuticals, 11010 Torreyana Road,

San Diego CA 92121, USA

gGilead Sciences Inc., 333 Lakeside Dr., Foster City, CA 94404, USA

hTorrey Pines Therapeutics, Inc., $11085 \mathrm{~N}$.

Torrey Pines Rd, Suite 300, La Jolla, CA 92037, USA

'BASF A.G., Ludwigshafen, Germany

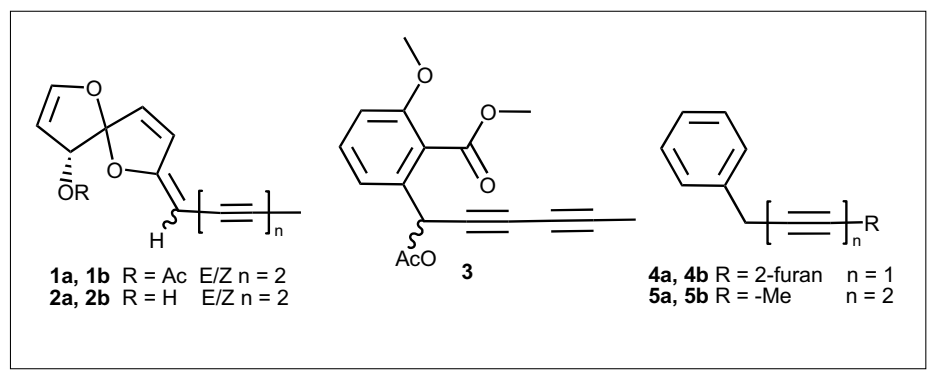

Fig. 1.

Cross-indication high-throughput screening (HTS) of the fungicide analog 6 (Fig. 2) elicited a weak herbicidal response at 500 $\mathrm{g} / \mathrm{Ha}$ on Stellaria but was inactive on Nasturtium, Agrostis and Digitaria species. The symptoms were unknown and the chemistry was attractive because it would be a new class of agrochemical compounds. [5] Therefore a combinatorial approach in collaboration with CombiChem Inc. ${ }^{[6 a]}$ was established to study the scope of this chemical class.

\section{CombiChem Library Generation}

The CombiChem approach used iteration and integration with automated synthesis and purification to refine computational models and discover new compounds.[6a] In this application, the iterative discovery strategy sought to maintain an optimal donor-acceptor-group relationship while further exploring chemical space around the original lead compound (Fig. 2).

Essential in this 'discovery process' was the desire to investigate modifications that would examine

i) physical property space

ii) the intrinsic elements required for activity and

iii) similarity to chemistry in the published domain.

Our strategy was to use high-speed synthesis (HSS) and classical synthetic methods to generate structure-activity relationships (SAR).

\section{Computational Methods}

Three rounds of the iterative discovery strategy were completed (Fig. 2). In each iteration, active and inactive data were 


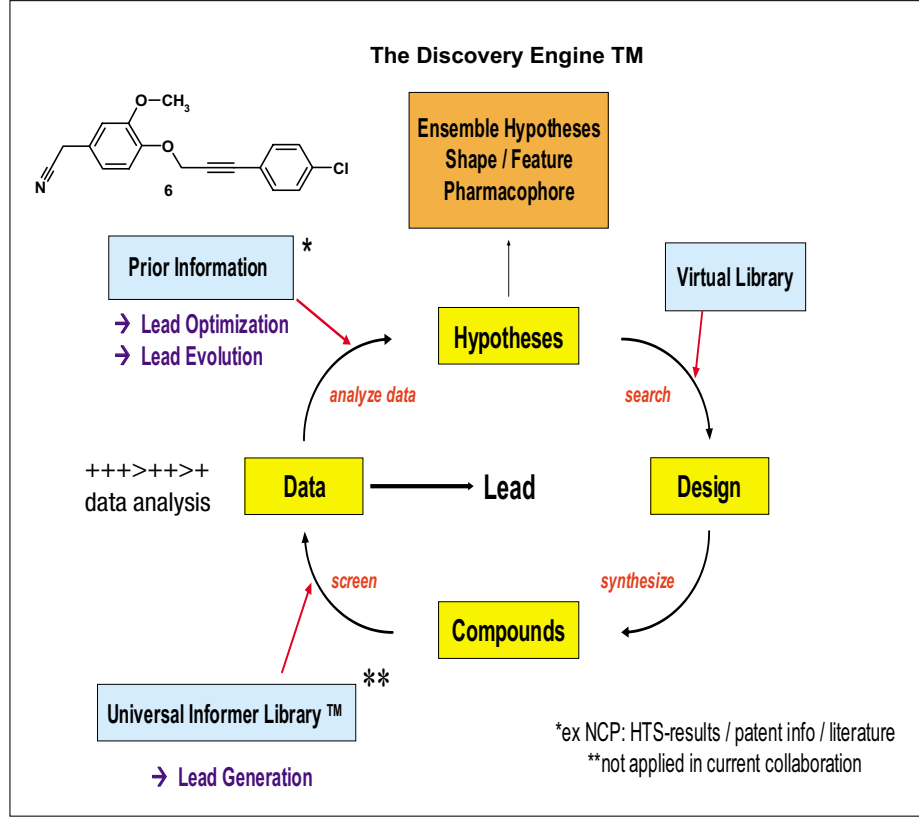

Fig. 2. Discovery process. Increasing biological activity

analyzed to derive an ensemble model composed of three-dimensional pharmacophores associated with herbicidal activity. These models were used to design new chemical libraries to explore and validate

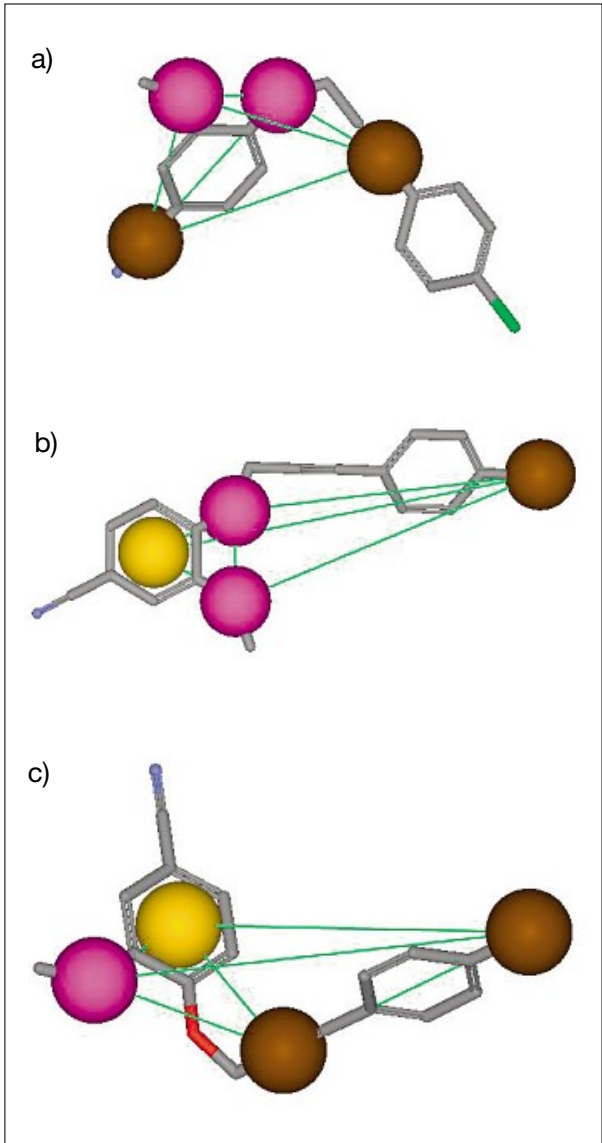

Fig. 3. Computation of molecule 6, (see Table 1) aligned to three examples of four-point pharmacophores associated with herbicidal effects. Each sphere represents a chemical feature point in the pharmacophore: hydrogen bond acceptors (pink), aromatic groups (yellow) and hydrophobic groups (brown). fabia is also observed. the pharmacophore space described by the model. With each iteration of design, synthesis and screening, the pharmacophore space of the ensemble model was evolved to encompass newly discovered active and inactive compounds. The iterative CombiChem approach to ensemble modeling has been described previously. ${ }^{[7-10]}$ The pharmacophore descriptor space was composed of 2-, 3-, and 4-point pharmacophores defined by a choice out of six feature types (hydrogen-bond acceptors and donors, hydrophobes, negative and positive ionizable groups, and aromatic groups) and their corresponding 3D distances (Fig. 3).[6b]

\section{Biology}

The biological response and symptomology are shown in Figs 4a and 4b.

With parallel synthesis, CombiChem synthesized in three cycles 1201 new com- pounds which contained 100 different pharmacophores. Biological screening at Novartis led to 15 compounds selected for further profile screening (Table 1). Improved activity was identified for compounds with a preference for $\mathrm{C}(4)$-hydrogen or $\mathrm{C}(4)$-cyano group in ring $\mathrm{A}$ or with a $\mathrm{C}(3)$-halogen or C(3)-acetonitrilo group in ring B (Fig. 5). The herbicidal activity of the unsubstituted analog 14 was confirmed in field tests and became the lead compound for this project.

Analysis of Table 1 showed that replacement of the $\mathrm{C}(4)-\mathrm{Cl}$ with a $\mathrm{C}(3)$-acetonitrilo in ring B (1 $v s \mathbf{4})$ or replacement of the $\mathrm{C}(4)$-acetonitrilo group in ring $\mathrm{A}$ with a $\mathrm{C}(4)$-cyano group (1 vs $\mathbf{6})$ resulted in $100 \%$ herbicidal control of the broad-leaf plants. Simultaneous change at both these positions gave a slightly less active analogue $\mathbf{2}$ on broad-leafs. Furthermore, the herbicidal activity is diminished in the absence of the $\mathrm{C}(2)$-methoxy group (4 vs $\mathbf{5})$. An additional $\mathrm{C}(4)-\mathrm{Cl}$ to the $\mathrm{C}(3)-\mathrm{Cl}$ in ring-B maintains herbicidal effects (3 vs 8). The C(3)-position in ring $\mathrm{B}$ is judged the most responsive position overall.

\section{Exploration of Structure}

The general synthetic route is shown in Scheme 1. ${ }^{[15]}$ Alkylation of substituted phenols 15 with propargylic bromide $\mathbf{1 6}$ in step i consistently gave $75-85 \%$ yields of intermediate phenolic ethers 17. The Sonogashira coupling ${ }^{[16]}$ was optimally performed in piperidine as solvent.[17] These new variations confirmed the weak herbicidal symptoms in subsequent biological screening.

\subsection{Structure Comparisons in the Patent Literature}

We postulated the same mode-of-action (MoA) for the Sankyo chemistry ${ }^{[18]}$ based on
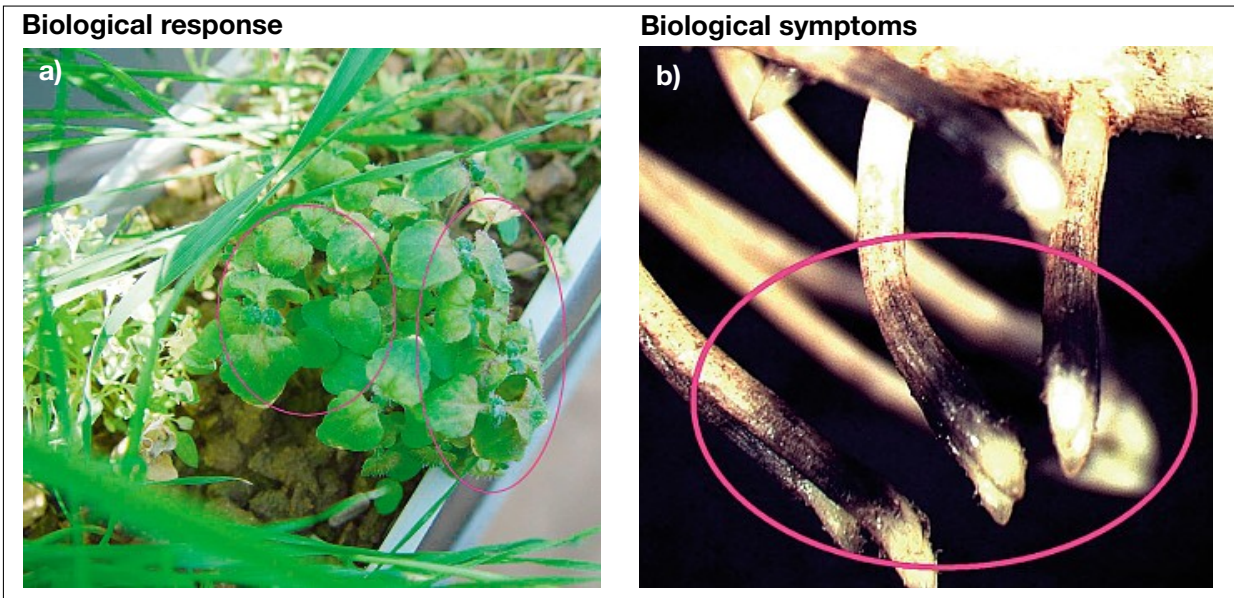

Fig. 4. a) Stellaria, chickweed: the mature plant showed symptoms of desiccation and curling of the leaves. b) Vicia fabia, field beans: circled area in photo. The symptomology of discoloration in Vicia 


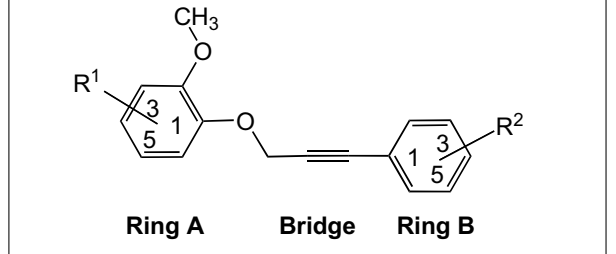

Fig. 5. Generic structure, see Tables 1 and 2

Table 1. Names in black = Broad leafs; names in green = grasses. Ratings of $3=90 \%$ activity; $2=50 \%$ activity; $1=10 \%$ activity. Application at $500 \mathrm{~g} /$ $\mathrm{Ha}$. Asterisk denotes the generic structure. Fig. 5 without a $2-\mathrm{OCH}_{3}$ group. More active values in red.

\begin{tabular}{|c|c|c|c|c|c|c|c|c|c|c|c|}
\hline \multirow[b]{2}{*}{ 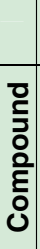 } & \multirow[b]{2}{*}{$\begin{array}{l}0 \\
\frac{0}{0}\end{array}$} & \multicolumn{2}{|c|}{ Substitutents } & \multicolumn{8}{|c|}{ High-Throughput Screen (HTS) } \\
\hline & & $\mathbf{R}^{1}$ & $\mathbf{R}^{2}$ & $\frac{\frac{\pi}{\frac{\pi}{\pi}}}{\frac{\omega}{\omega}}$ & $\frac{\pi}{\frac{\pi}{2}}$ & 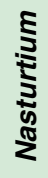 & $\begin{array}{l}\frac{n}{5} \\
\frac{0}{5} \\
\frac{7}{\square}\end{array}$ & 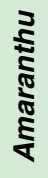 & 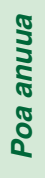 & $\frac{\xi}{\frac{5}{\delta}}$ & के \\
\hline 1 & 3.91 & $4-\mathrm{CH}_{2} \mathrm{CN}$ & $4-\mathrm{Cl}$ & 1 & 0 & 0 & 0 & - & - & - & - \\
\hline 2 & 2.68 & 4-CN & $3-\mathrm{CH}_{2} \mathrm{CN}$ & 3 & 2 & 2 & 0 & 3 & 0 & 3 & 1 \\
\hline 3 & 3.97 & 4-CN & 3-Cl & 3 & 2 & 3 & 0 & 2 & 0 & 3 & 1 \\
\hline 4 & 2.36 & $4-\mathrm{CH}_{2} \mathrm{CN}$ & $3-\mathrm{CH}_{2} \mathrm{CN}$ & 3 & 0 & 3 & 0 & 3 & 0 & 3 & 0 \\
\hline 5 & 2.62 & $4-\mathrm{CH}_{2} \mathrm{CN}^{*}$ & $3-\mathrm{CH}_{2} \mathrm{CN}$ & 2 & 0 & 2 & 0 & 2 & 0 & 1 & 0 \\
\hline 6 & 3.97 & $4-\mathrm{CN}$ & 4-Cl & 3 & 0 & 3 & 0 & 3 & 0 & 3 & 0 \\
\hline 7 & 4.12 & $4-\mathrm{CN}$ & $3-\mathrm{Br}$ & 3 & 0 & 3 & 0 & 3 & 0 & 3 & 0 \\
\hline 8 & 4.56 & 4-CN & 3,4-diCl & 3 & 0 & 2 & 0 & 2 & 0 & 3 & 0 \\
\hline 9 & 2.94 & $-\mathrm{H}$ & $3-\mathrm{CH}_{2} \mathrm{CN}$ & 3 & 1 & 3 & 0 & 3 & 0 & 3 & 1 \\
\hline
\end{tabular}

Test Species. The following plant species were used in primary and secondary screening. Broad-leaf weeds tested included chickweed (Stellaria media); pigweed (Amaranthus retroflexus); watercress (Nasturtium); black nightshade (Solanum nigrum); lambsquarters (Chenopodium album). Grasses tested: crabgrass (Digitaria sanguinalis); bluegrass (Poa annua); barnyard grass (Echinochloa crus-galli); giant foxtail (Setaria faberi); bentgrass (Agrostis).

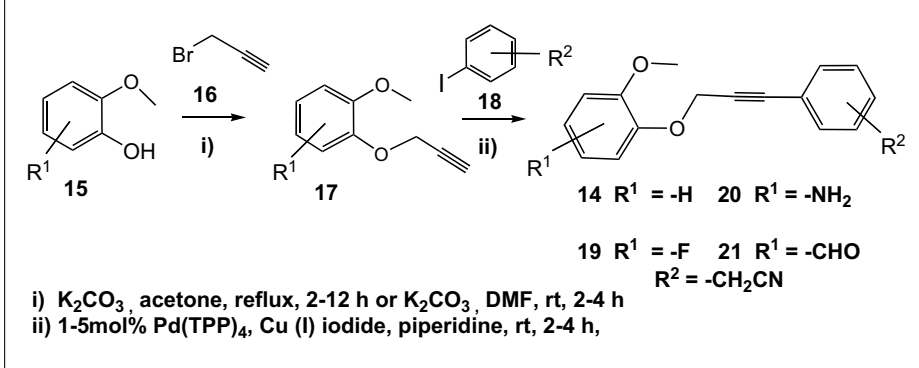

Scheme 1.

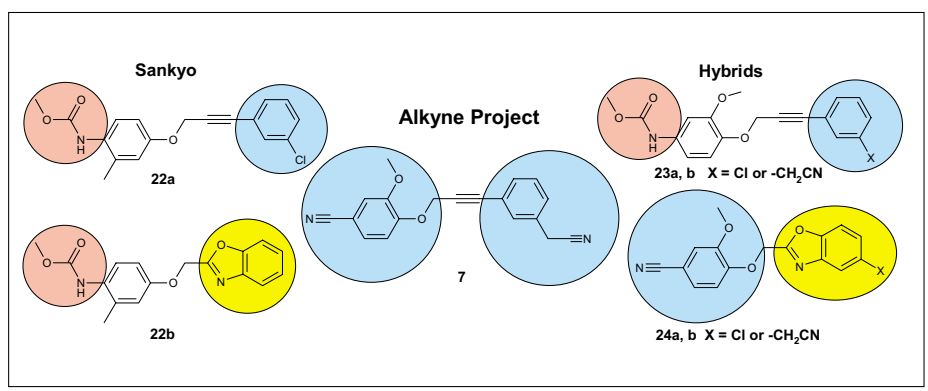

Scheme 2

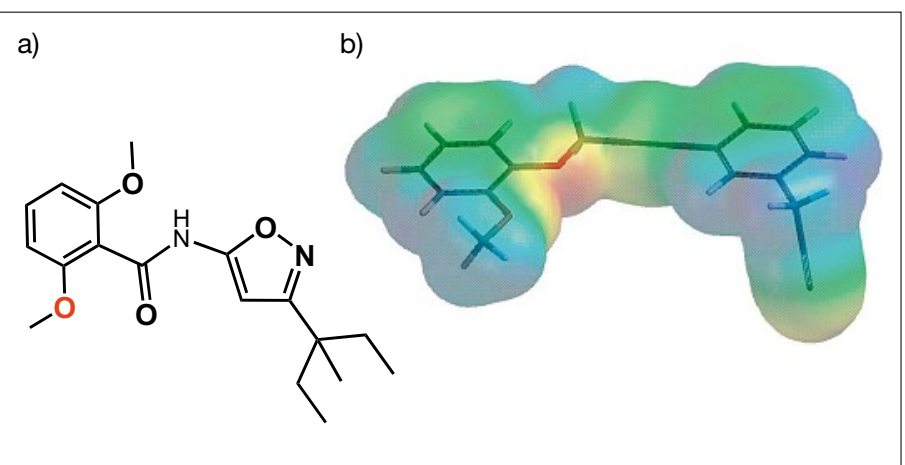

Fig. 6. a) Isoxaben; b) lead 14 a similar biological spectrum, symptomology and structural elements (Scheme 2). The active Sankyo analogs 22a,b showed that the bridge and ring $\mathrm{B}$ were exchangeable elements. Therefore the appropriate hybrids of Sankyo's chemistry[18] (red, yellow in Scheme 2) and Novartis' chemistry (blue) were synthesized. But the inactivity of compounds $\mathbf{2 3}$ and $\mathbf{2 4}$ implicated different requirements for biological activity and probably a different MoA.

In the course of systematic investigations, the $\mathrm{C}(4)-\mathrm{F}$ analog 19 was synthesized. This compound showed a tenfold-rate increase in herbicidal activity. Similarly fluorine was introduced at all positions in ring A of lead $\mathbf{1 4}$. The stronger C(4)-F bond effect on physical properties may improve uptake-transport to the target site. ${ }^{[19]}$ The ring $\mathrm{A}$ analogues with fluorine in positions $C(3), C(5)$ and $C(6)$ maintained herbicidal symptoms but were weaker herbicides. Moreover the C(4)-F may also improve the biological fit of the inhibitor at the active site.
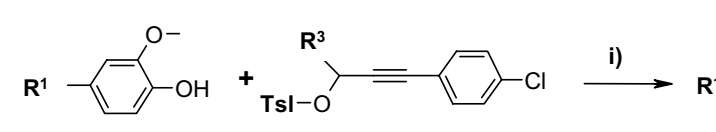

$\mathbf{R}^{1}=$ NHCOR 25

$29 a$

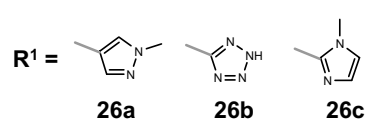

i) $\mathrm{K}_{2} \mathrm{CO}_{3}, \mathrm{DMF}, 50^{\circ} \mathrm{C}$

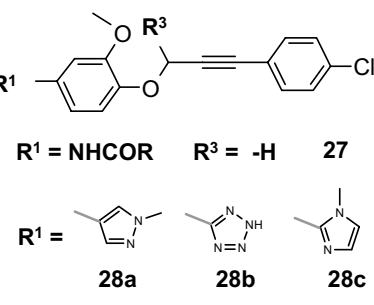

Scheme 3.

\subsection{Structural Overlap Comparison}

Although the MoA was not known at this stage of the project some observed symptomatic similarities to the known commercial broad-spectrum pre-emergence herbicide, isoxaben (Fig. 6a) were observed. This herbicide induces blackening of the leaves and swelling of roots in sugarbeets, a broad-leaf crop. Furthermore, the structural shape of isoxaben was compatible with our alkyne system (Fig. 6b). This led to introduction of different bridge types or replacement of either benzene ring with a heterocycle.

\subsection{Chemical Modifications of Ring A}

The HSS group synthesized a number of aniline derivatives 27 (Scheme $3 . \mathrm{R}^{1}=$ -NHCOR) in order to explore the physical property space to improve uptake or transport properties. Although the lipophilicity or Clog $\mathrm{P}$ varied from 1.2 to 6.8 most of these simple anilides 27 did not show improved biological activity.

Cyano-mimics such as pyrazole $\mathbf{2 6 a}$, tetrazole 26b or imidazole $\mathbf{2 6 c}$ intermediates (Scheme 3) were synthesized by literature methods utilizing C(1)-O-methyl-deprotection with thiolate salts. ${ }^{[20]}$ This strategy pro- 


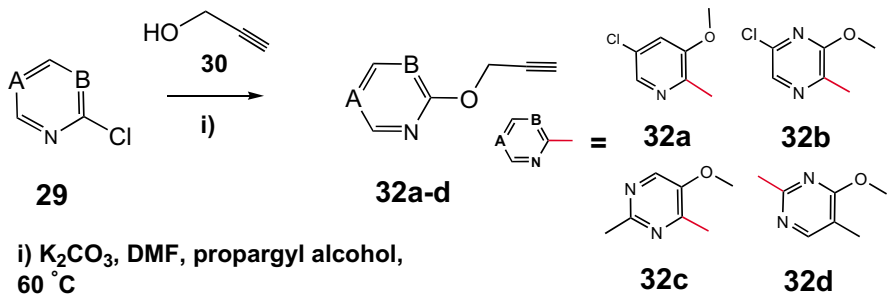

Scheme 4. Heterocyclic ring $A$

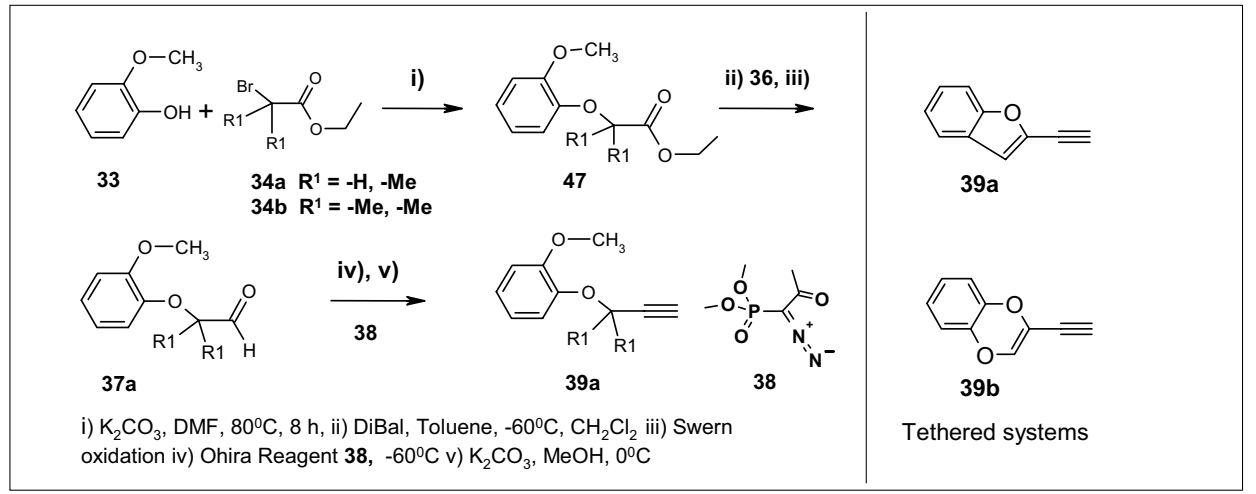

Scheme 5. Alternative synthesis of alkyne bridge

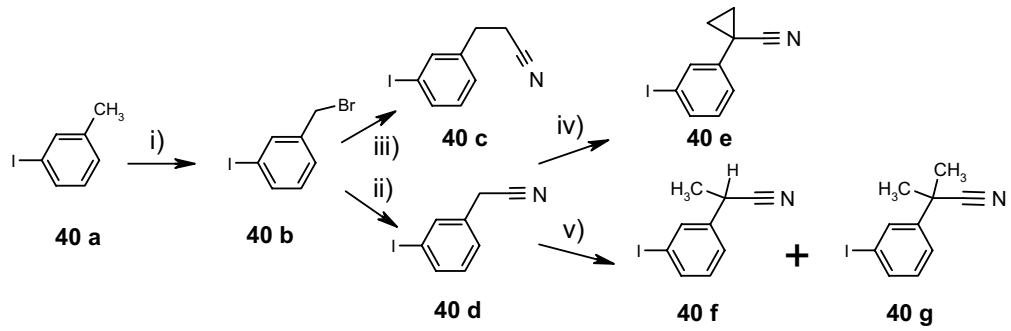

i) NBS, AIBN, dibenzoylperoxide ii) n-butyl) ${ }_{4} \mathrm{NBr}, \mathrm{KCN}, \mathrm{NaOH}$ aq, $\mathrm{CH}_{2} \mathrm{Cl}_{2}$, iii) LDA, acetonitrile, - $60^{\circ} \mathrm{C}$ iv) $\mathrm{BrCH}_{2} \mathrm{CH}_{2} \mathrm{Br}, \mathrm{NaH}, \mathrm{DMF}, \mathrm{rt}, 12 \mathrm{~h}$ v) n-butyl) ${ }_{4} \mathrm{NBr}, \mathrm{CH}_{3}-\mathrm{I}, \mathrm{NaOH}$ aq, $\mathrm{CH}_{2} \mathrm{Cl}_{2}$

Scheme 6. Ring B variations

duced three isosteric replacements for the cyano group but all analogues $\mathbf{2 8 a}-\mathbf{c}$ were biologically inactive.

A number of heterocyclic analogues were synthesized to evaluate the scope of variations for ring $\mathrm{A}$. These analogues were obtained by alkylation of propargyl alcohol 30 with halogenated pyridines $29 \mathbf{a}$, pyrazine $29 b$ and pyrimidines $29 \mathbf{c}-\mathbf{d},{ }^{[21]}$ to yield the corresponding ethers $\mathbf{3 0}$ for cross-coupling with 3-bromophenylacetonitrile 31a (Scheme 4).

\subsection{Chemical Modifications of the Bridge}

In order to obtain alkyl modifications of the bridge, the molecule was built up from ring B. Activation of the propargylic alcohol as a tosylate or mesylate $(\mathbf{2 9 a}, \mathbf{2 9}$ ) how- ever gave undesired elimination products (Scheme 3, $\mathrm{R}^{3}=-\mathrm{CH}_{3}$ ).

An alternative approach was undertaken whereby alkylation of catechol 33 with ethyl $\alpha$-bromoacetate $34 \mathbf{a}$, reduction of resulting ester 35 followed by Swern oxidation gave the phenoxyacetaldehyde 37a (Scheme 5, $\left.\mathrm{R}^{1}, \mathrm{R}^{1}=-\mathrm{H},-\mathrm{CH}_{3}\right)$. Subsequent Wittigreaction with Ohira reagent $\mathbf{3 8}$ produced the alkyne 39a in excellent yield. ${ }^{22]} \mathrm{Fi}$ nally, cross-coupling afforded the desired bridged-alkylated analogue $\mathbf{1 4 a}$ which was biologically weaker than the lead $\mathbf{1 4}$. Isosteric replacement of the triple bond with

i) a phenyl ring

ii) extension with another triple bond or

iii) incorporation of carbon, nitrogen or sulfur atoms for the propargylic $\mathrm{C}(1)$ - oxygen were detrimental to the herbicidal activity.

Restricted rotation of ring $\mathrm{A}$ or ring $\mathrm{B}$ by a tethered connection to the bridge i.e. benzofuranyl or 1,4-benzodioxinyl 39a,b respectively (Scheme 5) resulted in weaker analogues than the lead $\mathbf{1 4}$.

\subsection{Chemical Modifications of Ring B}

3-Iodophenylacetonitrile (40d) was produced by free-radical bromination and cyanation of the 3-iodobenzylbromide $(\mathbf{4 0 b})$. Phase-transfer alkylation ${ }^{[5 \mathrm{~d}]}$ of the arylcetonitrile 40d gave 40f, $\mathbf{4 0 g}$ whereas the lead 14 failed to react under the same conditions. Sodium hydride alkylation of arylacetonitrile 40d gave cyclopropane 40e in good yield (Scheme 6). Extension of the cyano group in 40c by LDA-alkylation of 3-iodobenzylbromide (40b) in acetonitrile gave the desired building block 40c. Subsequent cross-coupling gave the corresponding analogues but most of these modifications resulted in loss of herbicidal activity. However the pyridine ring $B$ analogue $\mathbf{4 1}$ did show significant herbicidal effects comparable to the lead molecule 14 (Table 2).

Palladium coupling was the most efficient with iodobenzene partners which readily cross-coupled at room temperature. Cross-coupling with bromobenzenes on the other hand gave variable results and often required microwave conditions, $150{ }^{\circ} \mathrm{C}$ for $15 \mathrm{~min}$. to give appreciable product. Attempts to utilize benzene triflate esters in the cross-coupling were unsuccessful except for meta-substituted benzenes. Thiophene and pyridine iodides 42, 43 respectively coupled efficiently. The pyridine analogues 42a, 42b showed moderate herbicidal activity and although thiophene, considered an isostere for benzene ${ }^{[23]}$ gave the inactive analogue, 43 . The relative position of the thiophene acetonitrile group may be critical. More significantly, the pyridine analogues encouraged us to look at more lipophilic functionality such as oxime-ethers rather than basic polar heterocycles to improve the herbicidal activity. The synthesis of oxime ethers 44, 45, 46a, 46b was accessible from the benzaldehyde analog 21 (Scheme 2). Their biological results (Table 2) showed a significantly improved broad-leaf weed spectrum.

\section{Lead Optimization}

\subsection{Field Results}

The field screening is the most critical phase, since here the herbicidal activity must withstand variations in physical parameters such as humidity, temperature and soil variations which can cause the compound to be poorly transported to the plant or where chemical instability decreases its 
Table 2. Secondary screen of broad-leaf plants. Ratings of $1=90 \%$ activity; $3=70 \%$ activity; $9=$ inactive. Application at $250 \mathrm{~g} / \mathrm{Ha}$. Asterisk denotes the generic structure. Fig. 5 contains a pyridine Ring B. Note that Table 2 ratings are reversed compared to those in Table 1. More active values in red.

\begin{tabular}{|c|c|c|c|c|c|c|c|c|c|c|c|c|c|c|c|}
\hline & \multicolumn{2}{|c|}{ Substitutents } & \multicolumn{13}{|c|}{ Broad-Leaf Weeds } \\
\hline 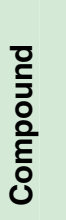 & $\mathbf{R}^{1}$ & $\mathbf{R}^{2}$ & $\begin{array}{l}\frac{\pi}{0} \\
\frac{2}{5} \\
\frac{1}{2} \\
\frac{2}{3}\end{array}$ & $\frac{\pi}{5}$ & 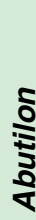 & 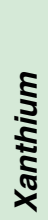 & $\begin{array}{l}\mathbb{8} \\
\& \\
\text { \& } \\
\vdots\end{array}$ & 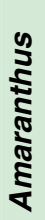 & $\begin{array}{l}5 \\
\frac{5}{\delta} \\
\vdots \\
\vdots \\
\frac{\delta}{0} \\
\delta\end{array}$ & 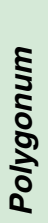 & $\begin{array}{l}\frac{\pi}{\delta} \\
\frac{1}{\delta} \\
\frac{1}{1}\end{array}$ & $\frac{\frac{n}{5}}{\frac{2}{\infty}} \frac{5}{\infty}$ & $\frac{\pi}{\frac{\pi}{2}}$ & 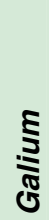 & $\frac{\mathbb{J}}{\frac{\delta}{0}}$ \\
\hline 14 & $-\mathrm{H}$ & $3-\mathrm{CH}_{2} \mathrm{CN}$ & 1 & 4 & 2 & 3 & 3 & 2 & 2 & 9 & 3 & 9 & 4 & 4 & 2 \\
\hline 19 & $4-F$ & $3-\mathrm{CH}_{2} \mathrm{CN}$ & 3 & 3 & 3 & 6 & 2 & 1 & 2 & 4 & 2 & 5 & 1 & 3 & 2 \\
\hline 41 & 4-F & $3-\mathrm{Cl}-4^{*}$ & 4 & 4 & 3 & 7 & 7 & 3 & 4 & 9 & 6 & 7 & 4 & 8 & 2 \\
\hline 42 & $-\mathrm{H}$ & $3-\mathrm{Me}_{2} \mathrm{CCN}$ & 3 & 4 & 3 & 2 & 3 & 6 & 9 & 9 & 5 & 5 & 5 & 6 & 3 \\
\hline 43 & $\begin{array}{c}4-\mathrm{CH}=\mathrm{N} \\
\text {-OAllyl }\end{array}$ & 3-Me & 1 & 3 & 3 & 7 & 3 & 1 & 3 & 9 & 4 & 5 & 1 & 4 & 2 \\
\hline $44 a$ & $\begin{array}{c}4-\mathrm{CH}=\mathrm{N} \\
-\mathrm{OMe}\end{array}$ & $3-\mathrm{Cl}$ & 2 & 2 & 3 & 7 & 3 & 2 & 2 & 9 & 9 & 9 & 4 & 4 & 2 \\
\hline $44 b$ & $\begin{array}{c}4-\mathrm{CH}=\mathrm{N} \\
-\mathrm{OMe}\end{array}$ & $3-\mathrm{CH}_{2} \mathrm{CN}$ & 1 & 3 & 3 & 8 & 4 & 2 & 3 & 9 & 5 & 6 & 4 & 5 & 1 \\
\hline 45 & $\begin{array}{c}4-\mathrm{CH}=\mathrm{N} \\
-\mathrm{OEt}\end{array}$ & $3-\mathrm{CH}_{2} \mathrm{CN}$ & 1 & 3 & 3 & 9 & 3 & 2 & 4 & 4 & 4 & 4 & 1 & 3 & 1 \\
\hline
\end{tabular}

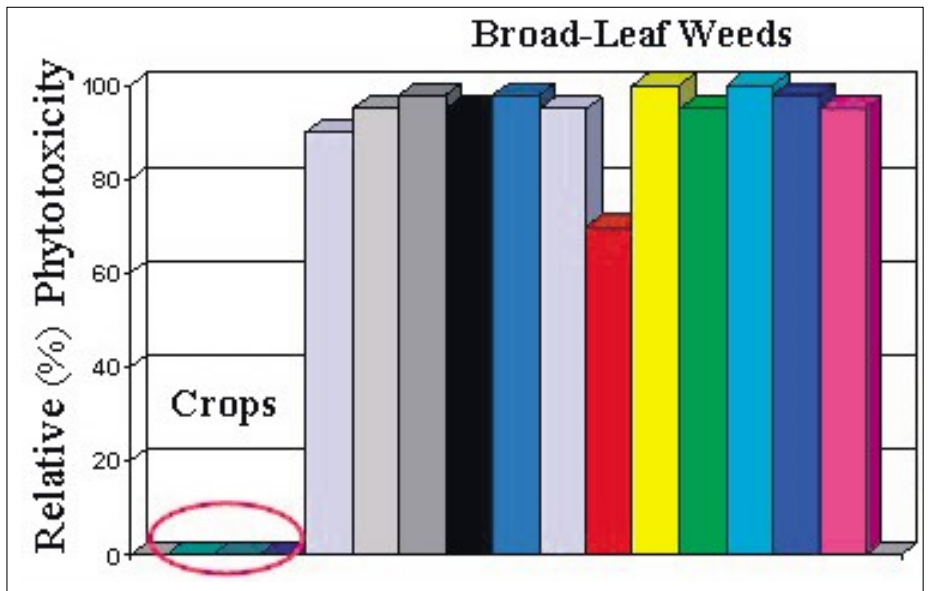

overall availability (Fig. 7). The C(4)-F analog 19 showed greater than $90 \%$ control of broad-leaf weeds without any phytotoxic effects on grass-like crops such as wheat or barley. Moreover, additional sedge and Echinochloa activity give this herbicide potential in rice applications.

\section{Conclusion}

A major challenge in the discovery of new chemistry lies in the progression from one structure class to another with improvement of desired biological activity. The initial HTS screening hit compound $\mathbf{6}$, showed hints of herbicidal effects but was weak overall. The biological symptoms indicate a novel MoA. Lead evolution using an established computational model en-
Fig. 7. Compound 19 applied at $500 \mathrm{~g} /$ Ha. Test crops: (from left to right) wheat, durum wheat, barley. Test species: Capsella, Chenopodium, Emex, Gallium, Kochia, Lamium, Matricaria, Papaver, Polygonum, Stellaria, Veronica hed. and Viola.

gave a flat SAR response. Biological attenuation appears to be restricted to simple functionality and that some specific substitutents appear essential, such as a $\mathrm{C}(2)$-methoxy group (ring $\mathrm{A}$ ) and a $\mathrm{C}(3)$ acetonitrilo group (ring B) for biological activity.

This successful lead-discovery project was subsequently promoted to optimization status. Although this lead development did not succeed in bridging the gap to another structure class, the potential for broad-spectrum development in crops still remains. The interest in broad-leaf control in crops such as cereals and overall improvement of the herbicidal activity remain the two primary objectives in its optimization project status for this novel chemistry and unknown MoA.

\section{Acknowledgments}

We are indebted to Syngenta FT-NMR specialist, Dr. Tammo Winkler and LC-MS expert, Dr. Andreas Stämpfli, currently at Hoffmann-La Roche, for valuable technical assistance. Also we thank our colleagues Drs. Kurt Nebel and Juergen Schaetzer for their professional support in the transfer of this project to optimization development and Dr. Anita Schnyder at Solvias AG, for important probe-experiments for large-scale applications of the Sonogashira chemistry. Finally, we thank our experienced chemistry practikanten, Fabien Dufour at University of Metz, and Olivier Sonntag at Nottingham University for their diligent synthetic contributions.

Received: November 25, 2007

[1] S. F. Donovan in ACS Symposium Series, 948, 'Synthesis and Chemistry of Agrochemicals VII', American Chemical Society, 2007, pp.7-22.

[2] K. Tietjen, M. Drewes, K. Stenzel, Combinatorial Chemistry and HighThroughput Screening 2000, 8, 589.

[3] a) H. Boehm, D. Banner, S. Bendels, M Kansy, B. Kuhn, K. Mueller, U. ObstSander, M. Stahl, Chem. Bio. Chem. 2004, 5, 637; b) P. L. Christensen, Recent Research Developments in Phytochemistry 1998, 2, 227. gave a first generation set of analogues. Subsequent combinatorial methodology using standard Sonogashira conditions produced a new set of molecules that resulted in a number of improved biological actives. In parallel, we focused on their structural similarity to known chemistry in the patent literature in order to clarify its MoA. In addition to the herbicidal effects, the novel discoloration symptoms in Vicia fabia were used to focus on what structural changes might be altered to delineate the scope of this new class of herbicide. After two further rounds of iterations, new molecules showed hints toward grass selectivity. Functional groups such as oxime-ethers 43-45 showed a trend toward a broadened biological spectrum. However it was observed that many structural modifications Martin, J. L. McLaughlin, J. Nat. Prod. 1998, 61, 781; b) H. Y. Li, S. Matsunaga, N. Fusetani, J. Nat. Prod. 1994, 57, 1464, c) V. U. Ahmad, N. Alam, J. Nat. Prod. 1995, 58, 1426; c) L. Hagmann, F. Jüttner, Tetrahedron Lett. 1996, 37, 6539.

[5] a) K. Hirai, A. Uchida, R. Ohno, 'Major Synthetic Routes for Modern Herbicide Classes and Agrochemical Characteristics', in 'Herbicide Classes in Development', Eds. P. Boeger, K. Wakabayashi, K. Hirai, Springer-Verlag, Berlin, Germany, 2002, pp.179-289; b) F. Cederbaum, A. De Mesmaeker, A. Jeanguenat, H-J. Kempf, C. Lamberth, A. Schnyder, M. Zeller, R. Zeun, Chimia 2003, 57, 680; c) G. W. Craig, M. Eberle, B. Irminger A. Schückenböhmer, Y. Laime, P. Müller, Heterocycles 2007, 71, 1967.
[4] a) N. H. Oberlies, L. L. Rogers, J. M. 
[6] a) CombiChem Inc., Molecular Design Group, 1804 Embarcadero Road, Suite 201, Palo Alto, 94303, USA; b) A molecular 'signature' was created for each molecule by generating a full conformational model using CONAN, ${ }^{[11]}$ and then mapping the presence or absence of all 2-, $3-$, and 4-point pharmacophores that are present in a molecule's conformers into a single bit string. Thus, each bit in this string corresponds to a particular pharmacophore that the molecule is able to present to a receptor $($ bit $=1)$ or not $($ bit $=$ $0)$. Flexible, feature-rich molecules may be able to present thousands of different pharmacophores. To select the subset of all pharmacophore hypotheses potentially associated with herbicidal activity, the signatures of all compounds (active and inactive) were systematically analyzed in the context of their associated activity data. The hypotheses were then ranked based on their ability to discriminate between actives and inactives across the entire data set. The ranking criterion used was 'information content' ${ }^{[12]}$ a function of both the active and inactive compounds. The top 100 pharmacophores were used to analyze virtual chemical libraries and to select compounds for the next round of synthesis and screening. This process was repeated for each of the three rounds. The first design cycle began with one compound in the propargyl template shown above exhibiting weak herbicidal activity, five chemically related inactive compounds and a set of chemically diverse inactives. Compounds libraries were designed to further explore the SAR around the weak lead compound. The designs included chemists' selections and computationally designed compounds selected for matching pharmacophores from an ensemble model derived from the initial weakly active lead compounds. A total of 268 compounds were synthesized and screened yielding 15 new active compounds. A second round of design and synthesis incorporating information from the new actives and inactives from the first round resulted in 18 additional active compounds out of 302 total compounds synthesized and screened. By the third round, 372 compounds were used for the training set including 16 compounds with the highest herbicidal activity rating of 3 against Stellaria and 16 additional compounds with weaker activity against Stellaria. The inactives now included compounds from the propargyl ether template in addition to other diverse compounds. The top 100 pharmacophores associated with herbicidal activity included three chemical feature types: hydrogen-bond acceptors, hydrophobes and aromatic groups (Scheme 2 shows three examples). Ninety-nine of the top 100 pharmacophores were four-point pharmacophores with the most commonly observed feature combinations: AcceptorAcceptor-Hydrophobe-Aromatic $(\mathrm{n}=$ 41) and Acceptor-Acceptor-HydrophobeHydrophobe $(\mathrm{n}=39)$. More than 4 million compounds on 11 different chemical scaffolds were evaluated using the round three model and a statistical sampling approach for virtual library searching. ${ }^{[13]}$ This sampling scheme estimates the rates that a virtual library will produce compounds matching a defined property such as model-matching compounds. Model matching compounds were defined as compounds which matched 40 or more of the 100 pharmacophores in the round three ensemble model. Three templates were selected for larger designed libraries based on their predicted rates of generating model-matching compounds, the success of test chemistries and chemical similarity to other chosen templates. For each of these three templates, an informative design strategy based on maximizing Shannon entropy was used to design combinatorial matrix libraries with maximal information about the ensemble. [14] For each template library design, monomer analogs of active compounds were forced into the design to address specific SAR questions. A second set of monomers were computational selected using informative design from a subset of monomers prevalent in model-matching virtual library compounds. Additional monomers were computationally selected to further explore the chemical space of each template. The result of this design method is a selection of molecules whose combination of on-bits (accessible pharmacophores) and off-bits (inaccessible pharmacophores) in their molecular signatures systematically investigates the pharmacophore hypotheses combined with compounds selected to address specific SAR questions.

[7] E. K. Bradley, P. Beroza, J. E. Penzotti, P. D. J. Grootenhuis, D. C. Spellmeyer, J. L. Miller, J. Med. Chem. 2000, 43, 2770.

[8] V. Molteni, J. Penzotti, D. M. Wilson, A. P. Termin, L. Mao, C. M. Crane, F. Hassman, T. Wang, H. Wong, K. J. Miller, S. Grossman, P. D. J. Grootenhuis, J. Med. Chem. 2004, 47, 2426.

[9] J. E. Penzotti, M. L. Lamb, E. Evensen, P. D. J. Grootenhuis, J. Med. Chem. 2002, 45, 1737.

[10] A. Smellie, R. Stanton, R. Henne, S. Teig, J. Comput. Chem. 2003, 24, 10.

[11] J. K. Lanctot, S. Putta, C. Lemmen, J. Greene, J. Chem. Inf. Comput. Sci. 2003, 43, 2163.

[12] P. Beroza, E. K. Bradley, J. E. Eksterowicz, R. Feinstein, J. Greene, P. D. J. Grootenhuis, R. M. Henne, J. Mount, W. A. Shirley, A. Smellie, R. V. Stanton, D. C. Spellmeyer, J. Mol. Graph. Model. 2000, 18,335

[13] J. L. Miller, E. K. Bradley, S. L. Teig, $J$. Chem. Inf. Comput. Sci. 2003, 43, 47.

[14] E. K. Bradley, J. L. Miller, E. Saiah, P. D. J. Grootenhuis, J. Med. Chem. 2003, 46, 4360.

[15] a) G. W. Craig, M. Eberle, M. Zeller, S. S. Bondy, D. D. Comer, S. Cheng, J. E. Penzotti, P. D. J. Grootenhuis, J. Ehrler, WO Patent Publication No. WO2001055066, 2001; b) J. Schaetzer M. Eberle, J. Wenger, S. Berteina-Raboin, K. Nebel, A. Stoller, R. G. Hall, S. S.
Bondy, D. D. Comer, J. E. Penzotti, P. D. J. Grootenhuis, WO Patent Publication No. WO2003013247, 2003

[16] a) K. Sonogashira, Y. Tohda, N. Hagihara, Tetrahedron Lett. 1975, 16, 4467; b) K. Sonogashira in 'Metal-Catalyzed Cross Coupling Reactions', Eds. F. Diederich, P. J. Stang, Wiley-VCH, New York, 1998, Chap. 5.

[17] R. Chinchilla, C. Najera, Chem. Rev. 2007, 107, 874 .

[18] M. Shimizu, T. Hiyama, Angew. Chem., Int. Ed. 2005, 44, 214.

[19] a) H. Sano, H. Komai, J. Kadotani, S Morimoto, JP Patent Publication No. JP11147866A, 1999; b) S. Sugai, H. Komai, N. Kudo, K. Sato, T. Honma, J. Kadotani, K. Koi, M. Ito, EP Patent Publication No. EP795550 A1, 1997.

[20] A. K. Chakraborti, L. Sharma, M. K. Nayak, J. Org. Chem. 2002, 67, 6406.

[21] C. Lamberth, Heterocycles 2006, 68, 561.

[22] a) S. Ohira, Synth. Commun. 1989, 19, 561 ; b) F. Eymery, B. Iorga, P. Savignac, Synthesis 2000, 185; c) Z. Wang, S. Campagna, G. Xu, M. E. Pierce, J. M. Fortunak, P. N. Confalone, Tetrahedron Lett. 2000, 21, 4007.

[23] C. G. Wermuth, J. de la Fontaine, 'Molecular Variations Based on Isosteric Replacements', in 'Practice of Medicinal Chemistry', Ed. C. G. Wermuth, 2nd edition, Elsevier, London, UK, 2003 , pp.189-214. 